\title{
A INDISSOCIABILIDADE ESPAÇO-TEMPO COMO ELEMENTO DE COMPREENSÃO DA CIÊNCIA GEOGRÁFICA
}

Ingrid Gomes da Silva ${ }^{1}$ Luiz Cruz Lima²

Resumo: O espaço geográfico é uma categoria e um conceito essencial em Geografia. O tempo, por sua vez, não é um conceito fundamental em suas investigações. Nesse sentido, propõe-se o debate do espaço e do tempo como categorias integradas, a fim de demonstrar a indissociabilidade desses conceitos, formando a categoria espaço-tempo para análises geográficas. Para tal discussão, utilizou-se uma abordagem teórica apontada pelo campo epistemológico do referido debate. Por meio dessa discussão, foram formulados novos conceitos em associação ao espaço - tempo fixo, tempo fluído e tempo flutuante -, a fim de denotar a indissociabilidade referida, que, por sua vez, constitui os resultados dessa discussão.

Palavras-chave: Espaço geográfico. Tempo. Geografia. Espaço-tempo. Categorias integradas.

\section{THE INDISSOLUBITY OF SPACE - TIME AS AN ELEMENT OF COMPREHENSION OF GEOGRAPHIC SCIENCE}

Abstract: The geographic space is a category and an essential concept in Geography. Time, in turn, is not a fundamental concept in his investigations. In this sense, it proposes the debate of space and time as integrated categories, in order to demonstrate the inseparability of these concepts, forming the space-time category for geographic analyzes. For such a discussion, used a theoretical approach pointed out by the epistemological field of that debate. Through this debate, new concepts were formulated in association with space - fixed time, fluid time and fluctuating time - in order to denote the referred inseparability, which, in turn, constitutes the results of this discussion.

Keywords: Geographic space. Time. Geography. Space time. Integrated categories.

\section{LA INDISOCIABILIDAD ESPACIO-TIEMPO COMO ELEMENTO DE COMPRENSIÓN DE LA CIENCIA GEOGRÁFICA}

Resumen: El espacio geográfico es una categoría y un concepto esencial en Geografía. El tiempo, a su vez, no es un concepto fundamental en sus investigaciones. En este sentido, el debate del espacio y el tiempo se propone como categorías integradas, a fin de demostrar la inseparabilidad de estos conceptos, formando la categoría de espacio-tiempo para los análisis geográficos. Para tal discusión, se utilizó un enfoque teórico señalado por el campo epistemológico del referido debate. A partir de ese debate, se formularon nuevos conceptos en asociación con el espacio - tiempo fijo, tiempo fluido y tiempo fluctuante - para denotar la inseparabilidad referida, que, a su vez, constituye el resultado de esta discusión.

\footnotetext{
${ }^{1}$ Universidade Estadual do Ceará - UECE, Programa de Pós-Graduação em Geografia - PROPGEO, Fortaleza, Brasil, ingrid_gomes10@outlook.com, https://orcid.org/0000-0003-3530-3557

${ }^{2}$ Universidade Estadual do Ceará - UECE, Programa de Pós-Graduação em Geografia - PROPGEO, Fortaleza, Brasil, I.cruzlima@uol.com.br, http://orcid.org/0000-0001-7595-9652
} 
Palabras clave: Espacio geográfico. Tiempo. Geografía. Espacio-tiempo. Categorías integradas.

\section{Introdução}

Há uma infinidade de proposições sobre a Geografia enquanto Ciência, que propõem diversas questões e rondam um amplo ideário, corroborando uma infinidade de compreensões. A pergunta "O que é Geografia?" é pauta desde a instalação da Geografia como Ciência, no final do século XIX, à atualidade. Por isso, pensar essa Ciência em definições exatas e rígidas, muitas vezes, remete a uma linearidade e a reducionismos, construindo um debate limitado.

Em decorrência disso, com o intuito de caminhar para a solução dessa dificuldade, muitas vezes, dogmatiza-se um conceito em uma relação categórica, ou seja, acredita-se que, para entender o caminho sugerido pela Geografia, é necessário entender seu objeto específico de estudo - o espaço e as relações nele contidas.

Essa dificuldade de compressão se filia ao que disse Santos (2008) ao questionar o que realmente está sendo definido - a Geografia ou o espaço. Santos (2008, p. 145) informa que a multiplicidade de definições rege uma tendência ao enfraquecimento da própria disciplina, em que, "se uma ciência se define por seu objeto, nem sempre a definição da disciplina leva em conta esse objeto".

Isso gera como consequência a não interpretação de que esse objeto da geografia - o espaço - não emerge sozinho. Na verdade, ele é dependente das relações que nele são efetivadas no tempo, ou seja, as relações sociais são condições sine qua non para compreensão, em geografia, do espaço social.

Assim, em busca de compreender a Ciência Geográfica, seu objeto, seus conceitos e pensamentos, é necessário caminhar para o entendimento das categorias analíticas que a compõem, a fim de depreender o objeto dessa Ciência Humana e tudo que nela está inserido e em constante produção e reprodução.

Dessa forma, entendendo a multiplicidade de investigações que essa Ciência abrange, objetiva-se, neste artigo, discutir as categorias que compõem o pensamento geográfico, avançando na ideia de objeto da geografia, sobretudo as análises de categorias que consolidam e fortificam a interpretação dessa ciência - o espaço e o tempo. Logo, é fato afirmar, obviamente, que essas categorias se modificam e se rearranjam à medida que avançam temporalmente os debates geográficos, o que significa dizer que elas se ampliam.

Nesse contexto, tem-se, então, a análise do espaço e do tempo como elementos centrais que encaminham a abordagem proposta. Ambos são conceitos 
bebidos sob diversos campos de análise. Entretanto, neste estudo, aponta-se que esses conceitos formam uma categoria una.

A partir disso, como base teórica-metodológica da pesquisa, esse artigo é apresentado por meio de uma estrutura retórica que apresenta o seguinte caminho: a) contextualização da temática; b) concatenação das bibliografias que discorrem sobre os conceitos; c) contra-argumentações, indagações e lacunas; d) apontamentos de posicionamentos científicos em reflexo ao estado da arte e proposições conceituais.

Portanto, o presente artigo apresenta as bases teóricas para entender a necessidade de pensar o tempo e espaço como categorias inerentes às análises geográficas, em que, inicialmente, emergem discussões que se pautam na solidificação da indissociabilidade dessas categorias, trazendo debates integrativos sobre sua perspectiva teórica e, por certo, faz advir a proposição de três novos conceitos relacionados ao tempo - tempo fixo, fluido e flutuante - em associação com a discussão espacial apontada por Harvey (2015) da visão tripartide do espaço - absoluto, relativo e relacional.

\section{Espaço e tempo ou espaço-tempo: conexão e associação}

O espaço geográfico é definido sobre inúmeras abordagens nos diversos momentos em que a Geografia vem sendo efetivada, em que ora aparece como receptáculo advindo da fase da Geografia Tradicional e na fase Teorética Quantitativa, ora aparece sendo condição de comportamento na fase da Geografia Crítica. Dessa forma, percebe-se que o conceito de espaço geográfico emerge a partir de diversos conflitos, compreendidos em momentos distintos da história.

Nesse sentido, o espaço se difere e se demonstra como conceito construído, ao longo do tempo, sob a lente de cada abordagem geográfica. Logo, pode-se questionar, então, se o correto seria adotar a ideia de espaço, único e singular, ou espaços, como um conceito plural. Será que um não é condição para o outro? Se assim o for, por que, então, a necessidade de se colocar um predicativo (geográfico) somado ao conceito espaço? Da mesma forma, será que a Geografia não necessita de outras categorias para melhor entender as bases geográficas?

A Ciência Geográfica ainda é, às vezes, inconstante e inconsistente nas pesquisas científicas ou nos meros devaneios dos pesquisadores, o que logo impõe a necessidade de buscar mais categorias que possam solidificar a base epistêmica e 
apontar que o espaço está no pensamento, na materialidade, na concretude, portanto, nas relações imbuídas em uma série de eventos diversos.

Assim, julga-se que o tempo é o elemento associativo ao espaço, conceitos que perfazem a compreensão plural da Ciência Geográfica. Essa abordagem, concebida no campo ontológico, advém de conceitos que integram a categorização espaço-tempo, como os de território, lugar, bairro, setores, zonas, áreas, paisagem, dentre outros. Nessa compreensão, fica a indagação: por qual motivo o tempo não é evidenciado como conceito fundamental no campo disciplinar geográfico?

Harvey (1967) afirma que, devido ao preconceito dos anglo-saxões, os geógrafos estiveram tradicionalmente negligenciando a dimensão temporal. A dimensão do tempo advinha das análises da geografia histórica, da geografia da retrospectiva ou do tempo geológico. Além disso, houve ainda a abordagem que o pensava apenas como elemento de algumas análises temporais, isto é, como processo. Milton Santos (2002) aponta que há quem trate o tempo também pela difusão das inovações, mas que, entretanto, virou apenas um apêndice da geografia do comércio.

O geógrafo brasileiro afirma, ainda, que o fato de a Geografia se eximir de incluir o tempo em suas análises tornou-a uma Ciência com uma grande "frouxidão conceitual". Assim, o autor se questiona:

Como ir além do discurso que prega a necessidade de tratar paralelamente o tempo e o espaço, do discurso de crítica dos outros especialistas que menosprezam esse enfoque, e do próprio discurso de autocrítica de uma geografia igualmente faltosa? Como ultrapassar o enunciado gratuito de um tempo unido ao espaço, mediante a relativização de um e de outro? Como traduzir em categorias analíticas essa mistura, que faz com que o espaço seja também o tempo e vice-versa? (SANTOS, 2002, p. 21).

É fato afirmar que se somam questionamentos dos motivos pelos quais a dimensão temporal é colocada em segundo plano nas análises geográficas, uma vez que, ao estudar o espaço, antes de mais nada, o (a) pesquisador(a), em sua investigação, também lida com a categoria tempo.

No campo científico, quando se trabalham perspectivas de discussões espaciais, a dimensão temporal normalmente é observada, entretanto existe uma diferença entre essa categoria ser utilizada apenas como apontamento metodológico e quando sua análise carrega, sobretudo, um rigor teórico e metodológico que se envolveu a priori de uma base epistemológica.

Percebendo essa problemática, pontuam-se os questionamentos: Ao estudar o espaço de uma cidade que, posteriormente, tornou-se metrópole, trata-se a 
necessidade de uma base temporal de análise? Ou, ao analisar os índices de erosão ou sedimentação de uma determinada faixa praial, isso não faz com que se julgue uma escala temporal de investigação para compor os resultados dessa determinada pesquisa?

Entende-se, na conjuntura desses questionamentos, que se faz o uso de uma dimensão que é temporal e não atemporal. Mas, se considerado dessa forma, em que momento é feita uma análise nas pesquisas sobre o caráter teórico do conceito de tempo que, porventura, modifica as ações socioespaciais determinadas por algum critério pertinente aos estudos? O tempo é, nesse instante, um dado de observação que compõe a metodologia utilizada ou uma base conceitual que detém um comprometimento científico de validade e, logo, repercute em hipóteses, que salvaguardam os fenômenos estudados?

É sobre esse contexto que Santos (2008) apontava ao fazer menção à gratuidade e à vagueza do conceito de tempo nas concepções geográficas. Talvez esse afrouxamento conceitual, tão cheio de rebaixamentos, abismos e más interpretações, como criticou Santos (2008), não esteja para a debilidade teórica e os múltiplos problemas de identidade que se fizeram salientes no movimento da revolução da Geografia nos anos 1970?

Nesse sentido, é fato afirmar que, tendo somente o espaço tal como estudado tradicionalmente na Geografia, o tempo aparece em segundo plano, sendo este mais discutido no campo da Física a partir da dimensão em que os fenômenos ocorrem, calculados e medidos; ou no campo da História, mediante de uma sucessão de períodos que pontuam a existência de cada objeto ou fenômeno; e, até mesmo, na Linguística como localização de fluxo dos acontecimentos, por intermédio do emprego de termos como - antes, agora, passado, presente, futuro, momento - ressaltando o modo temporal das ações (SILVA, 2010).

Nesse sentido, o que seria o tempo? O tempo pode carregar consigo diversas conotações em diferentes Ciências. Nessa concepção, ele se apresenta como categoria múltipla, que detém algum elo em comum com inúmeras discussões teórico-conceituais. Nessa conjuntura, questiona-se, ainda: Dentre esses campos que discorrem sobre o tempo, por qual motivo a continuidade da negligência do termo para a Ciência Geográfica ainda é tão presente?

Silva (2010, p.163) aponta que há dois posicionamentos filosóficos que compreendem o tempo: o dos subjetivistas e o dos objetivistas. A primeira perspectiva "concebe o tempo como sendo uma propriedade da alma", portanto que 
depende da sociedade para existir; os objetivistas, que, por sua vez, se apoiam nas Ciências Naturais, "concebem o tempo como um dado real da natureza, isto é, um aspecto físico do universo, uma dimensão na qual os seres existem", não necessitando da sociedade para se concretizar.

Nesse sentido, a autora chama atenção para a existência de uma falta de consenso das ideias sobre o tempo. Essa dualidade de visões insere uma contínua separação dialética e puramente geográfica da base racional de se pensar o tempo.

Se, para os objetivistas, o tempo é um elemento objetivo e concreto da natureza, em que os processos se realizam, para os subjetivistas, porém, o tempo está na dimensão da reflexão não necessariamente concreta de processos absolutos. Kant, por exemplo, afirma que o tempo é "uma condição subjetiva da alma humana, (intuição que é sempre sensível, isto é, na medida em que somos afetados por objetos), em si, fora do sujeito, não é nada" (KANT, 2001, p. 100).

O tempo seria compreendido, sob essa orientação, a partir de ideias análogas a esses pontos ou não? A partir dessas duas correntes que, ora ou outra parecem apresentar conflitualidades, Elias (1984) aponta que é necessário partir da percepção do tempo social, que é completamente mutável e não é preso a apenas um tipo de análise.

Espaço e tempo são conceitos essenciais na composição do mundo na vida do Homo sapiens sapiens (SZAMOSI, 1994), que se encontra a luz do pensamento filosófico na Grécia, por pensadores como Platão e Aristóteles (BRAGUE, 2006). Todavia, o tempo, comumente, encontra-se mais discutido no âmbito da mecânica clássica, na concepção newtoniana, e na teoria da relatividade geral implementada por Einstein, a partir da concepção da corrente objetivista (RENN, 2005).

Aristóteles (1931) apontava que o espaço era entendido como lugar, isto é, como posição de um corpo em relação aos outros (ABBAGNANO, 2003). Em associação a isso, o tempo era considerado sob a ideia de movimento, sendo o tempo "a medida do movimento segundo, o antes e o depois" (ARISTÓTELES, 1931, 017).

Newton, por seu turno, discorria que o espaço era um receptáculo que contém os objetos materiais (ABBAGNANO, 2003) e o tempo tinha caráter absoluto e relativo, em que o primeiro era o tempo exato e matemático, que por sua própria natureza, flui "uniformemente sem relação com nada externo, e também é chamado duração. O tempo relativo, aparente e comum, é uma medida sensível e externa da duração por meio do movimento" (NEWTON, 1978, p. 45). 
No entanto, Einstein (2001) sugere que não existe espaço nem tempo, mas sim um objeto único chamado espaço-tempo. Isso formula o que ele chama de contínuo quadridimensional, "cujo ponto de partida é a crítica à concepção de espaço e tempo [...] Este contínuo quadridimensional é formulado a partir do acréscimo da coordenada temporal às coordenadas utilizadas por Descartes (eixos x, y e z)" (FERREIRA; HELAYËL-NETO; BATISTA; JESUS; BATISTA, 2009, p. s.n).

Acompanhando as teorias desses três físicos, é possível perceber que a ideia de medição e exatidão de um elemento temporal é a intenção chave dessas discussões. Assim, pode-se constatar que o tempo carrega consigo um caráter numérico, tanto pelo teor da distância quanto pela apreensão de um intervalo de tempo pela sucessão contínua dos instantes.

Em contrapartida a isso, sobre o viés da corrente subjetivista, Piettre (1997) tece uma crítica sobre a necessidade da relação da subjetividade do tempo, desde Aristóteles até as discussões contemporâneas da Física Clássica, em que assinala uma negação filosófica do tempo, a partir de questionamentos sobre a existência do início e do fim da limitação dos conceitos.

Autores como Hegel (1995), Kant (1990; 2001), Heidegger (2011), Bachelard (2010), Leibniz (1988), Descartes (2007), Whitrow (2005) fazem menção ao tempo no plano da consciência e da realização, e não apenas da exatidão, denotando seu caráter plural. Sobre a ótica de tais autores o tempo em suma representa 0 movimento e a alma em direção a concepção da vida (REIS, 1994).

Bergson (2006) afirma que o tempo se associa à noção de duração, sendo a continuação de uma vida interior como transição ininterrupta. Na visão plantonista, Reis (1994) considera o tempo como instância do movimento, na passagem dos astros, das estações e na presença do dia e da noite. Diferentemente, Agostinho (1999) acredita que o tempo é uma atribuição da passagem do passado, do presente e do futuro que possui representação na alma dos sujeitos.

Entretanto a reflexão aqui proposta pauta-se na análise para além de abordagens pontuais e exatas, mas, sobretudo, em uma reflexão epistemológica. Assim, acredita-se que a união de abordagens, correntes e concepções sugerem a compreensão ampla do tempo para que possa fundamentar as discussões geográficas. Silva (2010, p. 173), acerca disso, aborda que:

Não existe uma substância correndo incessantemente que se chama tempo, nem um componente cerebral que permita ao homem ordenar sua vida em meio ao devir. Conceber o tempo como um dado transcendental, inato, independente da experiência das relações sociais é um dos pontos que invalidam as teorias clássicas. Partir do pressuposto que o tempo é único, 
seja subjetivo ou objetivo, e que todos os seres [...] compreendem e sentem a mesma coisa como sendo o tempo, é dizer que há algo absoluto, algo que pertença à categoria do eterno, do imutável.

É possível perceber, com isso, um contexto de multidimensões para se pensar o tempo. Em algumas visões, o tempo é um dado objetivo em que acontece determinada ação; em outras, porém, ele é a correspondência de como cada ação humana se delineia. Sobre isso, se questiona aqui o que há em comum entre as duas correntes.

$\mathrm{Na}$ conjuntura disso, pode-se concluir que, nas diversas atribuições filosóficas, nas concepções de diferentes autores e nos díspares campos do saber, é necessário um construto espacial para ocorrência das ações, que se estrutura, evolui e se altera para efetiva compreensão do tempo.

Nesse âmago, para enfrentar essa insolubilidade que se remete ao tempo como conceito fundamental na Geografia, entende-se que o espaço é elemento a priori para entender a materialização do tempo e sua efetiva transformação, visto que, "em cada época e em cada grupo, o mesmo símbolo pode adquirir significados e orientações diferentes sem perder sua função original" (SILVA, 2010, p. 178) e, por conseguinte, se comporta a partir de uma indissociabilidade que elucida a compreensão geográfica.

Vieira (2003) concorda sobre isso ao afirmar que:

O espaço é um componente da existência material e o tempo, a seqüência das transformações da matéria. Assim, o espaço e o tempo passam a ser concepções indissociáveis com formas e grandezas derivadas das formas e grandezas da matéria e de suas transformações (VIEIRA, 2003, p. 2).

Logo, julga-se a compressão da necessidade da indissociabilidade dos termos que compõem a categoria espaço-tempo e formulam bases para a compreensão espacial geográfica, pois o espaço só pode ser compreendido se observadas as temporalidades que o delineiam, de maneira que o tempo só pode possuir concretude se romper barreiras espaciais que realizam mudanças no espaço.

Haesbaert (1995, p. 31), ao discorrer sobre o tempo e o espaço, afirma que uma dissociação desses conceitos em nada auxilia o campo do saber geográfico, uma vez que o "tempo só existe porque pode ser materializado no espaço; espaço só existe porque está envolvido na dinâmica do tempo".

Kant (1990) aponta que a natureza do tempo e do espaço se liga à existência das coisas, que mostra, por sua vez, que a razão e a experiência estão na origem 
dos conhecimentos condicionados pela consciência, assim determinando a concepção dos sujeitos. Essa ideia, para o autor, relaciona-se intimamente com a metafísica, em que o movimento é figura essencial para se entender o tempo. Logo, "pensar sobre o tempo e o espaço não é o mesmo que estar no tempo e no espaço. [...] um conceito envolve o outro" (SOUZA, 2015, p. 105). Isso apreende uma gama de interpretações que neles evocam caracteres plurais e atribuições amplas.

Nessa conjuntura, é possível perceber diversas conotações de diferentes concepções de tempo, quer seja de nível filosófico, físico, histórico, técnico e métrico. No entanto, no nível geográfico, o debate não se faz tão presente, sobretudo nas discussões atuais.

Grandes geógrafos clássicos chamaram atenção, mesmo que de forma sintética, para associação do espaço e do tempo. A exemplo disso, Souza (2015) afirmava que Ratzel, em 1907, já dizia que o espaço vazio é impossível, ao mesmo tempo que é impossível também o tempo infinito, filiando-se a uma concepção aristotélico-kantiana.

Todavia, nos debates científicos atuais, a discussão do tempo sobre uma abordagem geográfica ainda se remete às espreitas como elemento metodológico de observação ao pensar o espaço, e não como uma conjunção ao se conceberem as diversas análises socioespaciais. Souza (2015, p. 105) questiona que:

\begin{abstract}
A Geografia para afirmar-se como ciência independente adapta ou reformula conceitos advindos de outros campos do saber, quase que desencontrada e esquecendo a originalidade dos termos. [...] Onde está a Geografia? Os geógrafos estão adormecidos em plena vigilância? [...] Ademais, pergunta-se: o espaço e o tempo em realidade existem como instâncias existências ou são criações humanas? São dimensões exteriores ou interiores? Espaço e tempo constituem uma ou duas instâncias?
\end{abstract}

É possível observar a série de questionamentos que o autor insere na tentativa de fazer os leitores refletirem na busca dos motivos que explicam o contínuo negligenciamento da associação espaço-tempo. Entretanto, é importante ressaltar que Souza (2015) não busca respostas concretas, pelo contrário, o autor caminha em instigar o raciocínio geográfico nessa componente de discussão, o que coaduna, por sua vez, nas intenções refletidas nesse debate proposto.

Logo, olhar para a categoria espaço-tempo como análise das transformações que se repercutem no espaço é, em suma, elucidativo e fiel para compreensão fidedigna da realidade vivenciada. Assim, é possível entender que a dimensão do tempo e do espaço é basilar para melhor compreender os processos que se sucedem no espaço social e natural. O tempo, sob essa ótica, parece estar como 
elemento congruente nessa base que perfaz as transições distintas. Santos aponta isso ao afirmar:

Seria impossível pensar em evolução do espaço se o tempo não tivesse existência [...]; é igualmente impossível imaginar que a sociedade se possa realizar sem o espaço ou fora dele. A sociedade evolui no tempo e no espaço. Tempo e Espaço conhecem um movimento que é ao mesmo tempo contínuo, descontínuo e irreversível. Tomado isoladamente, tempo é sucessão, enquanto o espaço é acumulação (SANTOS, 2008, p. 42).

Nesse par dialético sucessão e acumulação, em que o tempo é o transcurso e a sucessão dos eventos e em que o espaço perfaz o meio de excelência de acontecer a possibilidade dos eventos, a compreensão espacial geográfica se delineia, uma vez que tempo e espaço, nesse dimensionamento, são realidades históricas concretas e cuja indissociabilidade preconiza a existência de um quadro de composição teórica que notifica as formas, as funções e os processos socioespaciais.

Logo, é necessário entender as bases de cada conceito, fortificar suas cargas semânticas, diluir as barreiras no quesito teórico-metodológico para que se possa entender que nada se advém por acaso, uma vez que o acaso não é extensão fundamental de tempo e espaço.

Assim, é importante sair da inconsistência teórica e aprofundar o entendimento dos conceitos e categorias como essenciais na compreensão dos processos que se firmam no tempo e no espaço, o que repercute em discussões pertinentes para o comportamento da sociedade.

Souza (2013), quando aponta os conceitos fundamentais da pesquisa socioespacial, aborda uma metáfora explicando o que seria cada um deles. $\mathrm{O}$ autor assinala que, quando se pensa em algum processo para entender a realidade, é necessário "erguer edifícios". Para isso, precisa-se de tijolos e argamassa. Os conceitos, então, seriam os tijolos e as argamassas, sendo o conjunto dos dois a possibilidade de compreensão das investigações geográficas.

Enfim, ao atentar para essa metaforização sobre "erguer edifícios", a base categórica geográfica constitui-se de tijolos e argamassas, necessitando, em suma, de bases que possam reconhecer que os conceitos se complementam e que apontam significações coerentes para o auxílio nessa edificação necessária. Devese, assim, ir a favor das bases que explicam a natureza das coisas, dos entes e dos processos, bem como os fundamentos que avaliam o entendimento da totalidade. A integração, o diálogo e a conexão de saberes aliam-se para fortalecer a compreensão do espaço geográfico e, como legitima Sartre (1994), para que ocorra 
a compreensão de algo é necessário mudar, em alguma medida, as categorias que Ihe são pertinentes.

\section{O tempo e a Geografia: a necessidade de um debate}

É possível entender, então, que o espaço e o tempo são categorias conjuntas e básicas na composição da vida social. Além disso, é válido compreender que, ontologicamente, cada um configura significados distintos, que, porventura, se entrelaçam. Mas por qual motivo é contínua a negligência dessa conjunção em Geografia? Retorna-se a esse questionamento no qual calcou-se o ponto de partida desta discussão, meio e posteriores rebatimentos dessa altercação, uma vez que há uma insolubilidade da discussão, sua transformação em bases de senso comum ou até o discurso da sua clareza.

Harvey (2006, p. 142) chama atenção à falta de preocupação da análise do espaço em relação direta com o tempo. O autor afirmava que existia uma priorização conceitual onde "Marx, Marshall, Weber e Durkhein tinham isso em comum: davam prioridade ao tempo e à história e não ao espaço e à geografia, e, quando tratavam do espaço e da geografia, tendiam a considerá-los de modo não problemático".

O tempo, sua medição, seu registro, sua contagem sobre formas, dimensões e grandezas, tudo parece se encaixar e "tem seu lugar numa única escala temporal objetiva" (HARVEY, 2017, p. 187), entretanto, por mais que se encaixe numa padronização palpável, essa categoria vai muito além de uma objetivação.

Existem diversos sentidos de tempo. Por mais que acompanhe o raciocínio da Física Clássica, ele apresenta, muitas vezes, nuances diferenciadas no espaço, ou seja, cada sociedade pode interpretar o tempo sobre as mais díspares perspectivas, uma vez que se pode indagar que: o tempo, em dias, visualizado em comunidade rural é o mesmo tempo, em dias, em uma metrópole? É possível responder que sim e que não. Essa dúbia resposta se explica porque o tempo, enquanto conceito de sucessão de movimentos, que acarreta em temporalidades, é o mesmo em qualquer espaço terrestre, entretanto as relações socioespaciais que cada povo faz possibilitam ao tempo uma composição de forma diferenciada e singular, conforme seus afazeres e a produção para suas necessidades. Assim, na sociedade moderna, têm-se distintos sentidos de tempo, que, porventura, se intercruzam.

Depreende-se disso que os diferentes sentidos de tempo sugerem uma base de conflitos emergentes no espaço. É possível perceber isso quando se toma como exemplo o agronegócio, uma vez que esse setor em resumo se fundamenta em uma 
atividade baseada em uma cadeia produtiva, que se pauta na comercialização de produtos agropecuários. Para isso, são usados insumos que garantem a expansão da cadeia agrícola, no intuito de apressar o ciclo de produção, ou seja, acelerar o tempo para a circulação de capital. Desse modo, gera como consequência o uso de um tempo que não tem necessariamente a ideia do tempo natural preconizado pela natureza para a composição das bases agrárias.

Visto sob essa égide, o tempo, sim, é múltiplo. Seu caráter e sua gama de interpretações o objetivam como tal, refletindo-se no espaço, a partir de uma base de eventos e possibilidades de acontecimentos. Harvey (2006) afirma, assim, que é necessário refletir, principalmente no campo da Geografia, o fortalecimento desse conceito, não o apontando com um sentido único, mas uno, ou seja, é necessário apresentar a gama de interpretações que o tempo aborda, salvaguardando a validade científica distinta de cada compreensão, que aponta para uma interpretação integrada.

O tempo e o espaço apontam, então, processos socioespaciais e emergidos numa materialidade, na qual suas concepções são "criadas necessariamente por meio de práticas e processos materiais que servem à reprodução social" (HARVEY, 2017 , p. 189). Lembrando mais, essa reprodução da vida social se encontra em permanente mudança e, com ela, os territórios são constantemente transformados no tempo e no espaço.

A depreensão geográfica foca-se nesse contínuo processo de mudança, a qual, por sua vez, gera uma série de transformações de bases sobre outras, reordenando, assim, o que nela conjuga. Nesse meio, os próprios conceitos se reinventam e se refazem a fim de determinado progresso. Nas palavras do autor acima citado, o progresso nada mais implica do que a conquista do espaço, isto é, a derrubada das barreiras espaciais e a aniquilação do espaço pelo tempo.

Logo, a ideia inicial que questiona a negligência da conjunção do tempo ao conceito de espaço talvez possa ser solucionada se caminhar, continuamente, para o cercamento de bases interpretativas que transcendam, por sua vez, as barreiras impostas, tendo como necessidade as reconstruções até no campo epistemológico e que perfaçam a práxis geográfica desses saberes. O espaço-tempo não deve ser calcado no plano distante, quer seja no racionalismo ou no empirismo, mas a partir da sua integração, que pode caminhar para horizontes dessa discussão.

Isso corrobora o debate em que se insiste, no que tange à indissociabilidade entre o tempo e o espaço, visto que tais categorias, não podem ser compreendidas 
de forma desvinculada e, logo, associadas ao componente social que preconiza suas interpretações. O tempo, por conseguinte, é social; com ele e a partir dele, o espaço se legitima.

Assim, defende-se, nesta discussão, que o tempo, sob essa lente reflexiva, é: a) a dimensão de escala temporal métrica que se reflete em momentos distintos da história; b) o conceito fundamental geográfico que carrega consigo bases epistemológicas e ontológicas; c) condição e condicionante de preceitos socioespaciais a partir de modificações de infraestruturas e sistemas. Essas três ideias registram o que se acredita que seria o tempo para a Ciência Geográfica e a necessidade de sua profunda investigação nesse campo.

Portanto, para entender o tempo e compor a indissociabilidade dele com o espaço, propõe-se concepções que se associam aquele diretamente com este e que, assim, permitam demarcar tal união abordando uma atribuição de bases conceituais ao tempo, a fim de indicar um caráter integrativo dele com o espaço.

\section{O caráter integrativo espaço - tempo: tempo fixo, tempo fluido e tempo flutuante}

No movimento de construção das ideias supracitadas, apresenta-se a seguinte acepção: o espaço carrega um quadro múltiplo anexo ao tempo. O espaço e o tempo são histórias, fatos, reflexos e condições que delineiam o construto geográfico. A Ciência Geográfica se reflete, sobretudo, dessa e nessa correlação.

A Geografia é soma, e não divisão ou subtração. A Geografia é como um leque, em que cada elemento é composto de percepções heterogêneas e múltiplas e em que o espaço apresenta o sentido da totalidade que a emerge no campo da práxis. Assim, para a compreensão espacial geográfica e de suas categorias indissociáveis, deve-se talvez diminuir a necessidade de fechar definições do espaço, mas, sobretudo, procurar, na verdade, o que nomeia uma das célebres obras de Milton Santos (2002) - desvendar a natureza do espaço. A ideia de nomeação e a dificuldade de entender o que se deve compreender - se a Geografia ou se o espaço - está mais para analisar a sua natureza do que seu fato.

O fato se dá numa base temporal presente. A natureza é a união do pretérito que remete ao vivido. Logo, é imprescindível entender o processo contínuo numa base de transformações. Para isso, como escolha teórico-metodológica, a fim de depreender as bases refletidas entre as categorias da Ciência Geográfica, acredita- 
se na necessidade de compreensão da discussão apontada por Harvey (1980) - o caráter do espaço na tripartite: absoluto, relativo, relacional.

No entanto, é importante ressaltar que, em 1978, o geógrafo Milton Santos na obra Por uma Geografia Nova já chamava atenção para a noção do espaço quadrimensional, ou seja, afirmava que o enfoque espacial só podia ser entendido a partir de um enfoque temporal, considerando os "elementos formadores do espaço assim como as categorias analíticas ou de método, isto é, as categorias epistemológicas" (SANTOS, 2008, p. 250). Em soma a isso, esboça-se, neste artigo, uma relação conceitual proposta, relacionando a análise tripartite de Harvey (1980; 2015) associada ao elemento primordial para compreender o espaço-tempo, pela noção quadrimensional apresentada por Santos (2008).

Essa tripartite dita por Harvey (2017) não deve ser entendida no caráter de divisão e de análises distintas entre si, mas, sobretudo, na perspectiva de um tripé que compõe a compreensão do espaço geográfico. Na perspectiva harveyniana, de que se faz uso neste tópico de discussão, apresenta-se que o espaço pode ser considerado sob três lentes que tentam compor a natureza de seu significado, bem como a forma de observá-lo e, portanto, como entendê-lo.

Harvey (2015) afirma que o espaço absoluto é o estudado por Newton, Descartes e Euclides; é o dito fixo, em que se registram e são planejados os eventos. Geometricamente, é o espaço que é composto pelos sistemas de engenharia na captação dos fenômenos. Em Ciências Humanas, pode-se afirmar que ele é a representação administrativa no império do lócus, sendo a propriedade privada e o Estado, as instituições. Assim, a invariante que permeia todas essas compreensões é a de que o espaço concreto é permeado de racionalidade e lógica.

Harvey (2015), ao remeter sobre o espaço relativo, aborda que este se associa às discussões de Einstein. No sentido da Física, o conceito aparece como campo de múltiplas geometrias e que compõe um quadro espacial dependente do que está sendo relativizado por alguém. Para tal, ele não é só uma instância meramente física, mas que garante uma relação com o olhar do observador para analisar a geometria exata, ou seja, é o espaço que concerne à ideia do ponto de vista.

Sob isso, a ideia de tempo emerge, uma vez que, se é ele visto pelo observador, além de estar em uma posição variada, se vislumbra em óticas subjetivas diferentes. Nesse sentido, não se dá para "compreender o espaço independentemente do tempo, e isto implica uma modificação importante na 
linguagem, com uma passagem do espaço e do tempo ao espaço-tempo ou espaçotemporalidade" (HARVEY, 2015, p. 129).

Por fim, o espaço relacional é o espaço de Leibniz, como propõe Harvey (2015). Esse conceito, segundo discute o autor, faz objeção à ideia do espaço absoluto, uma vez que tudo que rege a vida está dentro do espaço, até mesmo Deus. No espaço relacional, isso não se efetiva, visto que não há elementos, tanto no espaço e quanto no tempo, fora do que os formou (na visão teológica, se Deus compôs o Universo, Ele não está apenas dentro deste, na verdade, Ele é a caricatura do Universo, não podendo estar dentro de algo, se o forma).

Assim, o espaço relacional não é algo interno a si mesmo, e sim o processo que o compõe a priori. Nesse espaço, além de serem observadas as características externas, são compreendidas, sobretudo, as ações internas, ou seja, é por intermédio destas que se pode chegar àquelas.

É nesse ponto que é perceptível o caráter temporal nessa assertiva. Além de o cérebro captar o espaço para si, ele carrega consigo ações externas numa base temporal que atinge o indivíduo, visto que um evento não é reflexo apenas daquele dado momento que está acontecendo, mas apresenta cargas de outras ações que já podem ter acontecido (HARVEY, 2015). Esse espaço abre mão, então, das medições e dogmas cartesianos, pois entende-se que a mensuração do espaçotempo é um erro, uma vez que nem tudo pode ser enumerado.

Então, o espaço, numa concepção analítica, teria caráter absoluto, relativo ou relacional? Harvey (1980) afirma que os três pressupostos não se separam e, se assim for, podem possuir os três caracteres. Nenhuma das três concepções está errada, apenas partem de princípios diferentes de observação. Portanto, muito mais que dogmatizar um objeto, é necessário entender a sua natureza.

O espaço não é nenhuma das três categorias somente, mas pode se tornar as três categorias se observado a partir de determinada lente metodológica da investigação a que se propõe o investigador. Nesse sentido, a pergunta central não é "o que é o espaço?", mas como é que diferentes práticas sociais criam, recriam e usam diferentes concepções espaciais.

$\mathrm{Na}$ conjuntura disso, é importante explicar e fundamentar o nível escolhido. Do mesmo modo, a questão não é o que é essa escolha, mas com que objetivo acontece a natureza de tal escolha. É essencial pensar sobre isso, uma vez que a finalidade de cada pesquisa científica carrega consigo aspectos teórico- 
metodológicos imprescindíveis que refletem, por sua vez, a postura da pesquisa e, de igual maneira, do(a) pesquisador(a).

Nota-se, diante disso, que é fulcral compreender que o espaço relacional está na intersecção do espaço relativo com o absoluto, pois, no espaço relativo, cabe o espaço absoluto e, por meio da conexão de ambos, pode-se aferir o espaço relacional. Entretanto, é importante perceber que o espaço absoluto não se comporta da mesma maneira. O fato está para a interação desses conceitos, em que, como o espaço absoluto é a propriedade sob o produto físico, relacionar o ponto de vista do observador ou as particularidades do ser não parece estar na sua dimensão ontológica. Diferente disso, o espaço relativo e relacional informam a necessidade de perceber as intempéries externas e internas do processo.

Logo, perceber a discussão dessas categorias geográficas nada mais é que entender que há a imersão em um enquadre espaço-temporal. O tempo pode não ser tão discutido, negligenciado, inconsistente e até "frouxo", tal como Santos (2008) afirmou, mas essa categoria compõe as bases iniciais em Geografia. Independente da perspectiva - se materialista, hermenêutica, empirista ou descritiva, o caráter integrativo espaço-tempo, repercute uma abordagem ontológica da Geografia.

Entendendo essa indissociabilidade espaço-tempo, acredita-se que o tempo também poderia compor as três acepções quando se relativiza o espaço, como aponta Santos (2008) ao falar da dimensão quadrimensional. Nesse momento, parte-se de uma ideia conceitual para a solidificação das partes pelo todo.

Nessa conjuntura, fica ainda o questionamento: há necessidade de dogmatizar o tempo em definições ao associar as bases discutidas acima? É complicado aferir certa necessidade, mas, partindo do princípio de que buscar a natureza dos termos auxilia na clareza epistemológica dos conceitos, pensa-se em tentar cooptar o início de uma base de discussão. É fato dizer que se sabe da complexidade desse empreendimento ao se propor uma ideia conceitual, mas o objetivo é auxiliar a possibilidade de um campo que ainda está se desenvolvendo. Para isso, propõe-se aqui uma discussão que visa pensar o tempo a partir da base harveyniana acerca do espaço, enquanto absoluto, relativo e relacional.

O tempo sobre caráter absoluto é o tempo métrico, exato, no qual os fatos começam e terminam naquele período e em que as subjetividades não são consideradas. Esse tempo chama-se tempo fixo. O tempo fixo é o das fronteiras, o de um determinado paradigma que não se modifica, o da razão fixa. O tempo fixo se comporta como legítimo em um espaço absoluto. Note-se que, nessa concepção, o 
acaso, por exemplo, não se visualiza, visto que pode ser um tempo cronológico que basta em si, sem incorporar as temporalidades presentes. Seria uma base de tempo atemporal, uma vez que não leva em conta a sucessão habitual de tempo.

Como segunda acepção, apresenta-se o tempo associado a perspectiva relativa, em torno da qual emerge a ideia da compressão espaço-tempo. Esse tempo se comporta na base discursiva de que cada investigação de períodos distintos na história, necessita a priori de quem observa dada realidade. Essa ideia parte do princípio de que cada tempo tem seu sentido distinto para diferentes povos. É o tempo da aceleração, da acumulação e do movimento. Esse tempo predica-se como fluido.

Por último, designa-se o tempo que se associa a perspectiva do espaço relacional. Quando Harvey (2015) aponta para esse espaço, o autor está calcado na soma do contexto absoluto e relativo-observador, por intermédio do que está endógeno e exógeno ao processo, remetendo, nessa orientação, ao quadro de composições das transformações que fazem os espaços se rearranjarem. Se, no espaço relativo, o movimento é ação fundamental, no relacional, esse movimento se abastece no critério de mudanças, uma vez que, se algo se movimenta, este se altera.

A esse tempo denomina-se de flutuante (associado ao espaço relacional), uma vez que reúne comportamentos internos e externos, ao passo que remete, pois, à soma de cada perspectiva. Se, no espaço relacional, o valor é uma componente de análise, no tempo flutuante, o valor admite o caráter de readmissões e movimentos que tendem a se rearranjar espaço-temporalmente. Nessa acepção, o tempo se comporta tanto sobre uma base concreta, que fomenta as transformações no seu sentido material, quanto nas manifestações abstratas, que tendem a reconfigurar os territórios e a assinalar relações socioespaciais heterogêneas.

Pensar as possibilidades dos eventos sobre essa categoria apresenta um quadro de multidimensões necessários aos debates. Nesse sentido, pensando de forma a sintetizar e clarificar essa integração conceitual, propõe-se o Quadro 1 abaixo: 
Quadro 1 - Teorema-síntese da tipologia do tempo

\begin{tabular}{|c|c|c|c|c|}
\hline Tempo & Espaço & Forma & Função & Processo \\
\hline Tempo Fixo & Absoluto & Linear & Métrica & $\begin{array}{c}\text { Cronológico, exato em } \\
\text { si }\end{array}$ \\
\hline Tempo Fluído & Relativo & Sucessão & Movimentação & $\begin{array}{c}\text { Aceleração, produção, } \\
\text { acumulação }\end{array}$ \\
\hline $\begin{array}{c}\text { Tempo } \\
\text { Flutuante }\end{array}$ & Relacional & Contínuo & $\begin{array}{c}\text { Endógena e } \\
\text { exógena }\end{array}$ & $\begin{array}{c}\text { Reestruturação } \\
\text { socioespacial }\end{array}$ \\
\hline
\end{tabular}

Fonte: Elaborado pelos autores.

Por meio desse quadro, assinala-se como cada espaço da visão tripartite de Harvey (2015) se relaciona a um tempo específico, que tende a enfatizar a dimensão quadrimensional. Nesse sentido, é possível refletir que cada espaço-tempo se concebe as variáveis de forma, função e processo (SANTOS, 2008).

Sintetizando o quadro acima, se o espaço absoluto se comporta de forma linear, a partir de um tempo fixo, sua função é métrica, por meio de processos cronológicos. Já se, no espaço relativo, apresenta-se uma base de sucessão, permeada pela função de movimentação que coloca em voga o processo de produção, o tempo se comporta como fluido. Em contrapartida, pensando no espaço relacional, o tempo admite caráter flutuante, de forma contínua, com funções endógenas e exógenas, por meio do qual poderão se vislumbrar processos de quebra/ruptura, a exemplo da reestruturação socioespacial.

O tempo, como conceito, está embebido do caráter de medida. Isso evoca a ideia do contexto geográfico quando se pensa nesse sentido e não apenas em um contexto geométrico. Assim, o tempo se define como variável geográfica, visto que a medida não se comporta como quantificação, mas sobre uma análise empírica com significação espacial (SANTOS, 2008).

A regência da sucessão habitual de tempos formula-se no espaço-tempo, bases cujo valor remete à necessidade de acumulação para efetivação de algo. Isso traduz tanto o espaço relativo quanto o relacional. Assim, em meio a essa movimentação, fundamenta-se um tempo flutuante de ação, a fim de cooptar os meandros das transformações socioespaciais.

O tempo não é simplesmente um produto, mas um produtor de uma base material e imaterial. A soma do sistema espaço-tempo, então, é em suma fiel para entender a totalidade dos processos geográficos, de maneira a perceber a horizontalidade entre espaço e tempo. 


\section{Considerações Finais}

Neste artigo, teve-se como objetivo o debate dos conceitos de tempo e espaço como categorias integradas, a fim de demonstrar sua indissociabilidade. Para isso, partiu-se das considerações de Santos (2002, 2008) e Harvey (1967, $1980,2006,2015,2017)$ acerca desses conceitos, a fim de compreender a base sólida da categoria espaço-tempo para análises geográficas.

Assim, ante à discussão aqui proposta, é fato perceber a importância da dimensão do tempo quando se evoca a base analítica do espaço (HAGERSTRAND, 1967). Logo, propôs-se questionamentos e reflexões que suscitam a importância do conceito de tempo para compreensão do espaço, e não o negligenciamento daquele em detrimento deste.

Nesse sentido, discutir tal imbricação categórica para a Ciência Geográfica significa calcar categorias e conceitos que dão base à compreensão de diferentes análises socioespaciais. Compreende-se que discorrer sobre o espaço e o tempo como categorias conjuntas, unas e integradas, é essencial para a solidificação das investigações geográficas. Portanto, a proposição dos conceitos de tempo fixo, tempo fluido e tempo flutuante, que se relacionam na discussão harveyniana, tenta auxiliar na consolidação da categoria espaço-tempo e propõe novos caminhos para se pensar a Geografia.

Na reflexão proposta, o tempo é a base de movimento que marca a sucessão continuada da sociedade, necessitando de um longo aparato de reflexões, e não de dogmas fechados. Assim, o tempo não tem forma e não apresenta uma estrutura física concreta, mas se comporta a partir de mecanismos que preconizam e marcam as ações e os fenômenos.

É nesse bojo que, ao refletir sobre a produção do espaço, entende-se a dimensão espacial geográfica como um produto social. Sendo assim, é de suma importância para essa Ciência somar bases que evoquem um conteúdo teórico capaz de dimensionar categorias e fortalecer os debates.

A integração espaço-tempo, então, é a ponte necessária para tentar responder às questões que estão constantemente calcadas no temário geográfico. Assim, o tempo e o espaço se vislumbram como categorias primeiras para a discussão do pensamento geográfico. Portanto, conceber um quadro que tente dialogar com os conceitos tempo e espaço e auxilie na solidificação da categoria 
espaço-tempo é essencial, visto que os reducionismos sobre essa temática são recorrentes.

É necessário sair da inconsistência teórica e recorrer à relevância de um debate epistemológico para compreender como os processos se firmam no tempo e no espaço. Pensar a epistemologia significa, por conseguinte, pensar a proposição do ato de produzir conhecimento geográfico.

Nessa perspectiva, filiar-se a essa abordagem demonstra a tentativa de suscitar caminhos, perspectivas e reflexões para pensar a relevância da indissociabilidade das categorias tempo e espaço como discussão central para a Ciência Geográfica.

\section{REFERÊNCIAS}

ABBAGNANO, N. Dicionário de Filosofia. 4. ed. São Paulo: Martins Fontes, 2003.

AGOSTINHO, S. Confissões. São Paulo: Nova Cultural, 1999.

ARISTÓTELES. Physique. Paris: Belles Lettres, 1931.

BACHELARD, G. A Intuição do instante. 2. ed. Campinas: Verus, 2010.

BERGSON, H. Duração e simultaneidade: a propósito da teoria de Einstein. São Paulo: Martins Fontes, 2006.

BRAGUE, R. O tempo em Platão e Aristóteles. São Paulo: Loyola, 2006.

DESCARTES, R. Princípios da Filosofia. 2. ed. São Paulo: Rideel, 2007.

FERREIRA, R. A.; HELAYËL-NETO, J.; SIQUEIRA-BATISTA, R.; DE JESUS, V. B.; SIQUEIRA-BATISTA, R. O espaço e o tempo, entre a Ciência e a Filosofia: notas para o ensino de Física. ENCONTRO NACIONAL DE PESQUISA EM EDUCAÇÃO EM CIÊNCIAS, 7, 2009, Florianópolis, Anais... Florianópolis: UFSC, 2009.

EINSTEIN, A. A teoria da relatividade espacial e geral. Rio de Janeiro: Contraponto, 1999.

ELIAS, N. Sobre o tempo. Rio de Janeiro: Jorge Zahar, 1984.

HAESBAERT, R. Desterritorialização: entre as redes e os aglomerados de exclusão. In: CASTRO, I. E. de.; GOMES, P. C. da C.; CORRÊA, R. L. (Org.). Geografia: conceitos e temas. Rio de Janeiro: Bertrand Brasil, 1995, p. 165-205.

HÄGERSTRAND, T. Innovation difusion as a spatial process. Chicago: University of Chicago Press, 1967.

HARVEY, D. Models of the evolution of spatial pattern in human Geography. In: CHORLEY; HAGGET. Integrated models. Methuen, 1967, p. 85 - 123.

HARVEY, D. A justiça social e a cidade. São Paulo: Hucitec, 1980. 
HARVEY. D. A produção capitalista do espaço. São Paulo: Annablume, 2006.

HARVEY. D. O espaço como palavra-chave. Revista em pauta, Rio de Janeiro, v. 13, n. 35, p. $126-152$, jul. 2015.

HARVEY. D. Condição pós-moderna. 13. ed. São Paulo: Edições Loyola, 2017.

HEGEL, G. W. F. Enciclopédia das Ciências Filosóficas em compêndio. A Ciência da Lógica. Tradução Paulo Meneses e José Machado. São Paulo: Loyola, 1995.

HEIDEGGER, M. Ser e tempo. 5. ed. (Tradução revisada e apresentação de Márica Sá Cavalcante Schuback; posfácio de Emmanuel Carneiro Leão). Petrópolis: Editora Universitária São Francisco, 2011.

KANT, I. Princípios metafísicos da Ciência da Natureza. (Tradução Artur Mourão). Lisboa: Edições 70, 1990.

KANT, I. Crítica da razão pura. Lisboa: Fundação Calouste Gunbenkian, 2001.

LEIBNIZ, G.W. Novos ensaios sobre o entendimento humano. (Tradução de Carlos Lopes de Mattos). São Paulo: Nova Cultural, 1988.

NEWTON, I. Mathematical principles of natural philosophy. Chicago: Britannica Great Books; 1978.

PIETTRE, B. Filosofia e Ciência do tempo. Tradução: Maria Pires de Carvalho. Bauru: EDUSC, 1997.

REIS, J. C. Tempo, história e evasão. Campinas: Papirus, 1994.

RENN, J. A física clássica de cabeça para baixo: como Einstein descobriu a teoria da relatividade especial. Revista Brasileira de Ensino de Física, v. 27, n. 1, p. 27-36, 2005.

SANTOS, M. A natureza do espaço: técnica e tempo, razão e emoção. São Paulo: Hucitec, 2002.

SANTOS, M. Por uma Geografia Nova: da crítica da Geografia a uma Geografia Crítica. 3. ed. São Paulo: HUCITEC, 2008.

SARTRE, J.P. Em defesa dos intelectuais. São Paulo: Ática, 1994.

SILVA, N. L. M. O tempo social de Norbert Elias: uma proposta de superação ao conhecimento dicotômico do tempo. Mneme - Revista de Humanidades, Rio Grande do Norte, v. 11, n. 27, p. $162-180$, dez. 2010.

SOUZA, M. D, de. A Geografia e o estudo do espaço e do tempo: a contribuição de outras ciências (uma nota crítica). Revista Tamoios, São Gonçalo, n. 2, p. 102-112, jul/dez. 2015.

SOUZA, M. L. de. Os conceitos fundamentais da pesquisa sócio-espacial. Rio de Janeiro: Bertrand Brasil, 2013.

SZAMOSI, G. Espaço e tempo: as dimensões gêmeas. Rio de Janeiro: Jorge Zahar, 1994.

VIEIRA, E. F. O tempo-espaço: ficção, teoria e sociedade. Caderno EBAPE.BR, Rio de Janeiro, v.1 n.1, p. $1-7$, ago. 2003. 
WHITROW, G. J. O que é tempo? uma visão clássica sobre a natureza do tempo. (Tradução Maria Ignez Duque Estrada). Rio de Janeiro: Jorge Zahar, 2005.

\section{NOTAS DE AUTOR}

\section{CONTRIBUIÇÃO DE AUTORIA}

Ingrid Gomes da Silva - Concepção. Coleta de dados, Análise de dados, Elaboração do manuscrito, Participação ativa da discussão dos resultados.

Luiz Cruz Lima - Participação ativa da discussão dos resultados; Revisão e aprovação da versão final do trabalho.

\section{FINANCIAMENTO}

Apoio financeiro do Conselho Nacional de Desenvolvimento Científico e Tecnológico (CNPq) na forma de bolsa.

\section{CONSENTIMENTO DE USO DE IMAGEM}

Não se aplica

\section{APROVAÇÃO DE COMITÊ DE ÉTICA EM PESQUISA}

Não se aplica.

\section{CONFLITO DE INTERESSES}

Não se aplica.

\section{LICENÇA DE USO}

Este artigo está licenciado sob a Licença Creative Commons CC-BY. Com essa licença você pode compartilhar, adaptar, criar para qualquer fim, desde que atribua a autoria da obra.

\section{HISTÓRICO}

Recebido em: 12-10-2019

Aprovado em: 05-07-2020 